\title{
A small proportion of community-associated methicillin-resistant Staphylococcus aureus bacteraemia, as compared to healthcare-associated cases, in two South African provinces
}

Olga Perovic ${ }^{1,2}$, Ashika Singh-Moodley ${ }^{1,2}$, Nelesh P Govender ${ }^{1,2,3}$, Ranmini Kularatne ${ }^{2,4}$, Andrew Whitelaw $^{5}$, Vindana Chibabhai ${ }^{2}$, Preneshni Naicker ${ }^{3}$, Nontombi Mbelle $^{6}$, Ruth Lekalakala ${ }^{7}$, Vanessa Quan $^{8}$, Catherine Samuel $^{5}$ and Erika Van Schalkwyk ${ }^{1}$ for GERMS-SA

Centre for Healthcare-Associated Infections, Antimicrobial Resistance and Mycoses, National Institute for Communicable Diseases, Johannesburg, South Africal

Department of Clinical Microbiology and Infectious Diseases, School of Pathology of the University of the Witwatersrand and National Health Laboratory Service, Johannesburg, South Africa ${ }^{2}$

Division of Medical Microbiology, Department of Clinical Laboratory Sciences, Faculty of Health Sciences, University of Cape Town and National Health Laboratory Service, Groote Schuur Hospital, Cape Town, South Africa ${ }^{3}$

Centre for Human Immunodeficiency Virus and Sexually Transmitted Diseases, National Institute for Communicable Diseases, Johannesburg, South Africa ${ }^{4}$

National Health Laboratory Service, Stellenbosch, Stellenbosch University, Stellenbosch, South Africa ${ }^{5}$

Department of Medical Microbiology University of Pretoria and National Health Laboratory Service ${ }^{6}$

Department of Medical Microbiology, University of Limpopo and National Health Laboratory Service, Polokwane, South Africa $^{7}$

Division of Public Health Surveillance and Response, National Institute for Communicable Disease ${ }^{8}$

Corresponding author email addresses:

olgap@nicd.ac.za; olga.perovic@nhls.ac.za; 


\begin{abstract}
We compared the proportion of cases of CA-MRSA and HA-MRSA bacteraemia among patients at five hospitals in Gauteng and Western Cape provinces in South Africa then described the molecular characteristics and antimicrobial susceptibility trends. This was a cross-sectional study using data collected by enhanced surveillance for Staphylococcus aureus bacteraemia.
\end{abstract}

A total of 2511 cases of $S$. aureus bacteraemia were identified from January 2013 to January 2016. Among 1914 cases of S. aureus, 557 (29.1\%) cases were identified as MRSA infection. Forty-four cases (44/1914 [2.3\%] of all S. aureus cases) were considered CA-MRSA infection and 513/1914 (26.8\% of all cases) had HA-MRSA infection; the majority were neonates. CA-MRSA constituted 7.9\% (44/557) of all cases of MRSA infection. $S$. aureus isolates demonstrated significantly reduced susceptibility to the following classes of antimicrobial agents: macrolides, tetracyclines, aminoglycosides, and cotrimoxazole, in 2015 compared to 2013 (p <0.05). Of the 557 MRSA isolates, $484(87 \%)$ were typed for SCCmec element and spa-types: the most common SCCmec type was type III $(n=236,48.76 \%)$ followed by type IV $(n=144,29.76 \%)$. The most common spa-types were t037 $(n=229$, $47.31 \%)$ and $\mathrm{t} 1257(\mathrm{n}=90,18.60 \%)$. Of 28 isolates selected for MLST, the most common STs were ST239 and ST612 of clonal complex (CC8) (n=8 each) and a novel ST (ST4121) was obtained for one isolate. This study demonstrates that $S$. aureus bacteraemia is common in South African academic centres and characterized by HAMRSA SCCmec III and IV types. A small proportion of CA-MRSA cases were caused by a few sequence types.

\title{
Keyword
}

Staphylococcus aureus bacteraemia; MRSA; Epidemiology of community vs. hospital MRSA; Surveillance for antimicrobial resistance

\section{Introduction}

Staphylococcus aureus is a major human pathogen that causes a wide range of clinical infections such as bacteraemia, endocarditis, arthritis, osteomyelitis, lung infections, skin and soft tissue and device-related infections (1). S. aureus is a commensal organism in about $30 \%$ of the human population (1). The epidemiology of S. aureus bacteraemia has been poorly described in low- and middle-income countries (LMICs) compared to highincome countries (HICs) $(1,2)$. While the case-fatality for $S$. aureus bacteraemia was approximately $80 \%$ in the pre-antibiotic era, this has remained persistently high (15\%-50\%) over the past several decades, partly owing to the emergence of methicillin-resistant $S$. aureus (MRSA) in the 1960s (1). Historically, MRSA isolates, which are 
resistant to $\beta$-lactam antibiotics, were confined to healthcare facilities. However, in the mid-1990s, the emergence of community-associated MRSA (CA-MRSA) strains, which cause infections among patients with no previous exposure to the healthcare environment, resulted in a considerable shift to CA-MRSA-associated disease in HICs in North America, Asia, Europe and Australia, but less so in LMICs (2, 3, 4). The overall incidence of S. aureus bacteraemia has been stable over the past two decades, but MRSA rates have fluctuated and since 2005, HICs including the United States, Canada, United Kingdom, France and Australia have described significant reductions in MRSA bacteraemia through population-based active surveillance $(1,5)$. The incidence of CA-MRSA in LMICs is less well described and this highlights the need for surveillance in order to determine the burden of disease. This is not simple because CA-MRSA and HA-MRSA are not easily distinguished and case definitions for both involve numerous variables such as epidemiological and clinical features, which are required in conjunction with molecular characterization of a large staphylococcal cassette chromosome mec (SCCmec). SCCmec types I to III are traditionally assigned to hospital strains and types IV to VI to community strains but this distinction has become less clear in the last few years. The largest proportion of cases of $S$. aureus bacteraemia (both methicillinsusceptible and resistant) occurred among children aged less than one year in a previous report from South Africa (6). This report also showed a strong association between HIV-infection and MRSA bacteraemia (6).

To our knowledge, no South African studies have yet described the proportions of MRSA bacteraemia that are community versus healthcare-associated using epidemiological, clinical and molecular criteria. In this study, we compared the proportion of cases of CA-MRSA and HA-MRSA bacteraemia among hospitalised patients at five sentinel surveillance hospitals in Gauteng and Western Cape provinces in South Africa, evaluated factors associated with CA-MRSA versus HA-MRSA and compared in-hospital outcomes between the two groups. We also described the molecular characteristics and antimicrobial susceptibility trends over a three-year period, to guide clinicians in antimicrobial stewardship (AMS) programmes and to establish baseline antimicrobial resistance profiles of $S$. aureus isolates for guideline and policy formulation.

\section{Methodology}

\section{Study design and population}

This was a cross-sectional study using data collected by active, laboratory-based surveillance for S. aureus bacteraemia, through the GERMS-SA enhanced surveillance programme. Five tertiary public-sector hospitals, Helen Joseph Hospital [HJH] with 900 beds serving estimated population of 1 million, Steve Biko Academic Hospital at Tshwane District [SBAH] with 832 beds for 402980 population, Charlotte Maxeke Johannesburg 
Academic Hospital [CMJAH] with 1088 beds intended for 4.4 million people from Gauteng Province and Groote Schuur Hospital [GSH] with 893 beds serving population of 1.8 million from Western Cape, and Tygerberg Hospital [TBH] with 1384 beds serving population of 1.9 million from the Western Cape that started surveillance one year later on $1^{\text {st }}$ January 2014 .

\section{Case definitions}

A case was defined as a person of any age accessing public-sector healthcare at any one of the five hospitals during the period of surveillance with a blood culture specimen positive for S. aureus. All positive specimens within 21 days of the first positive specimen contributed to a single case while subsequent positive specimens were considered part of new cases. All cases of $S$. aureus bacteraemia, where $S$. aureus was found to be nonsusceptible to oxacillin or cefoxitin, were classified as cases of MRSA infection.

Criteria to distinguish community- and hospital-associated MRSA

A number of criteria were used to distinguish CA from HA-MRSA bacteraemia. A case of CA-MRSA bacteraemia was defined as a patient with 1) MRSA isolated from a blood culture specimen $\leq 48$ hours of admission to hospital and 2) no contact with a healthcare facility within one year prior to the current episode of MRSA infection (including prior dialysis, prior surgery and prior admission to a long-term care facility). A patient with MRSA isolated $>48$ hours after admission or with any prior healthcare contact was considered to be a case of HA-MRSA infection.

\section{Data collection}

GERMS-SA surveillance officers used standardised case report forms (CRFs) to collect demographic, clinical and treatment data from consenting patients with laboratory-confirmed S. aureus bacteraemia. Data were also obtained from medical and laboratory records. Isolates from these patients were submitted to the National Institute for Communicable Diseases (NICD) for confirmatory identification, antimicrobial susceptibility testing, confirmation of mecA gene and genotyping. Completeness of surveillance data was checked for the time period, 1 January 2013 to 31 January 2016, using the National Health Laboratory Service Corporate Data Warehouse, which houses information from routine laboratory testing and reporting. 


\section{Statistical analysis}

Demographic and clinical characteristics of cases were summarised and compared using Chi squared/ Fisher's exact tests for categorical data and Student's T-test/ Wilcoxon ranked sum tests for continuous data. We calculated proportions by dividing the number of CA-MRSA and HA-MRSA cases by the total number of S. aureus bacteraemia cases, as well as, by the number of cases with MRSA bacteraemia. Multivariable logistic regression analysis was performed to evaluate factors associated with CA-MRSA versus HA-MRSA and to compare inhospital outcome between the two groups. Exposure variables (including age, sex, hospital, province, clinical diagnosis, body temperature at diagnosis, mental status, mechanical ventilation, cardiac arrest, prior MRSA, prior surgery, prior dialysis, previous admission to a long-term care facility, HIV-infection, participation in contact sports, living or working in crowded facilities, and pre-existing medical and surgical conditions) were independently evaluated as risk factors for MRSA-type and mortality by univariate analysis. Variables with pvalues $<0.2$ were included by forward stepwise manual addition into two multivariable models. A p-value of $<0.05$ in the multivariable models was considered as statistically significant.

\section{Microbiology}

\section{Phenotypic methods}

S. aureus isolates were submitted by diagnostic laboratories on Dorset transport medium (Diagnostic Media Products, NHLS, Sandringham). Organism identification was confirmed using the Vitek 2 GP card (bioMerieux, France). Susceptibility testing was performed on the MicroScan Walkaway system (Siemens Healthcare Diagnostics, USA) using the Positive MIC Panel Type 33. Categorical results and susceptibility profiles of most tested antimicrobial agents were based on the Clinical and Laboratory Standards Institute (CLSI) interpretative criteria (7); for fosfomycin interpretation of MICs was performed by using EUCAST interpretative criteria 2016 recommendations (8) and mupirocin MICs interpretation was based on manufacturer recommendations. The $\mathrm{MIC}_{50}$ and $\mathrm{MIC}_{90}$ (minimum inhibitory concentrations needed to inhibit the growth of $50 \%$ and $90 \%$ of organisms, respectively) were determined for all tested agents. 
Molecular methods

DNA extraction

Pure bacterial colonies were re-suspended in $400 \mu \mathrm{l}$ TE buffer. This was vortexed briefly and heated at $95^{\circ} \mathrm{C}$ for $25 \mathrm{~min}$ to allow bacterial cell lysis to release the DNA. Centrifugation followed at $12000 \mathrm{rpm}$ for 3 min to pellet the cellular debris. The supernatant was then aliquoted and stored at $-70^{\circ} \mathrm{C}$ for further investigations.

Polymerase chain reaction (PCR) screening for mecA and mecC genes in MRSA isolates

The Light Cycler 480 II instrument (Roche Applied Science, Germany) was used for the real-time PCR amplification of the methicillin resistance determinant, mecA and the species-specific gene, nuc which were amplified in a multiplex assay using the Light Cycler 480 Probes Master kit (Roche Diagnostics, IN, USA) with previously published primers and probes (9). In the absence of mecA, the G-Storm (Somerton Biotechnology Centre, UK) thermal cycler was used for conventional PCR-based amplification of the methicillin resistance determinant, mecC using the Qiagen Multiplex PCR kit (Qiagen, Germany) with previously published primers (10).

\section{SCCmec typing}

All mecA-positive MRSA isolates were typed by multiplex PCR using the Qiagen Multiplex PCR kit (Qiagen, Germany) and previously published primers (11).

Spa-typing

The spa gene was amplified using previously published primers (12) and the Amplitaq Gold DNA Polymerase kit (Applied Biosystems, CA, USA). Purified PCR products (Qiagen Purification kit; Qiagen, Germany) were sequenced (Inqaba Biotech, South Africa). Sequences were assembled using CLC Bio main workbench (Qiagen, Germany) and analysed using the Ridom StaphType ${ }^{\mathrm{TM}}$ software (Ridom GmbH, Würzburg, Germany).

\section{Multilocus sequence typing (MLST)}

For our hospital-associated infection $(\mathrm{n}=513)$ group, four isolates belonging to each of the five most common spatypes (t037, t1257, t012, t045 and t064) were selected for MLST. For our community-associated infection ( $\mathrm{n}=44)$ group, the following spa-types were observed: $\mathrm{t} 037, \mathrm{t} 1257 \mathrm{t} 064$ and $\mathrm{t} 032$. Two isolates belonging to the t037 and 
t1257 spa-types were selected for MLST; and one isolate each was observed and sequenced for the t064 and t032 spa-types. Since t032 was observed in the community-associated infection group, we also included two isolates belonging to this sequence type in our hospital-associated infection group. Primers amplifying 7 reference genes were used (13). Amplification was performed using the Amplitaq Gold DNA Polymerase kit (Applied Biosystems, CA, USA). Purified PCR products were sequenced (Inqaba Biotech, South Africa). Sequences were assembled using CLC Bio main workbench (Qiagen, Germany) and analysed using the online database (https://pubmlst.org/).

\section{Results}

Community-associated MRSA and hospital-associated MRSA

A total of 2511 cases of $S$. aureus bacteraemia were identified from January 2013 through to January 2016, including 597 cases with no corresponding isolates (missing or non-viable) detected by review of the laboratory information system. This accounted for 2414 discreet patients, as 76 patients had more than one episode of infection. Among 1914 cases of $S$. aureus bacteraemia with a viable isolate, confirmed molecular identification and full susceptibility profile, 557 (29.1\%, 95\% confidence interval [CI] 27.1-31.2) cases were classified as MRSA infection (Figure 1). Forty-four cases (44/1914 [2.3\%] of all S. aureus cases) were considered CA-MRSA infection and 513/1914 (26.8\% of all cases) had HA-MRSA infection. CA-MRSA constituted 7.9\% (44/557) of all cases of MRSA infection. 


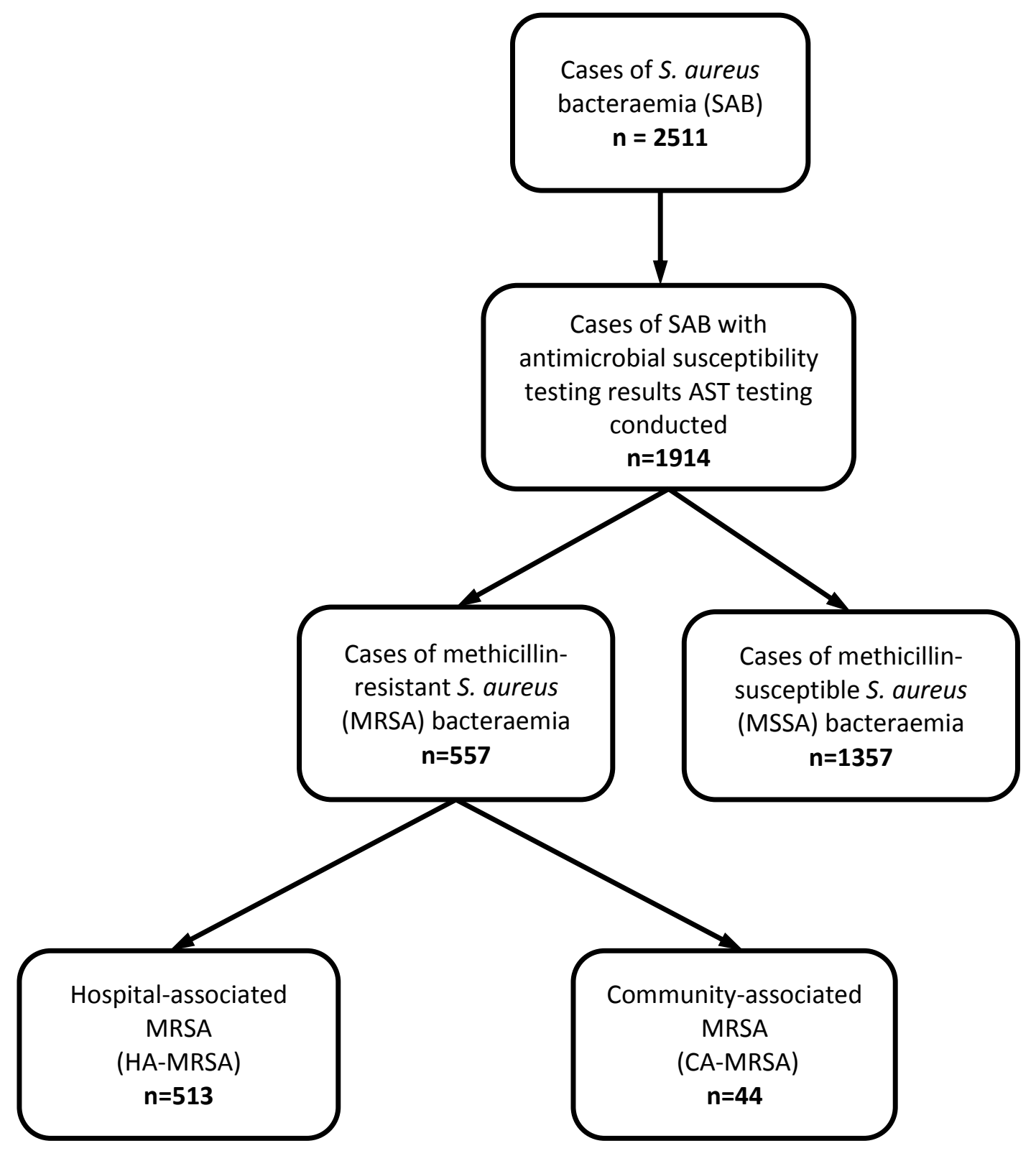

Figure 1: Flowchart of cases of Staphylococcus aureus bacteraemia among patients at five sentinel hospitals in South Africa, January 2013 to January 2016. AST=antimicrobial susceptibility testing 
Table 1: Demographic and clinical characteristics of patients with hospital-associated MRSA (HA-MRSA) and community-associated MRSA (CA-MRSA) at five sentinel hospitals in South Africa, January 2013 to January $2016(n=557)$.

\begin{tabular}{|c|c|c|c|c|c|c|c|}
\hline \multirow[t]{3}{*}{ Patient characteristics } & \multicolumn{7}{|c|}{ Type of MRSA $(n=557)$} \\
\hline & \multicolumn{2}{|c|}{$\begin{array}{l}\text { HA-MRSA } \\
(\mathbf{n}=\mathbf{5 1 3})\end{array}$} & \multicolumn{2}{|c|}{ CA-MRSA $(n=44)$} & \multicolumn{2}{|c|}{ Total } & \multirow[t]{2}{*}{ p-value } \\
\hline & $\mathbf{n}$ & $\%$ & $\mathbf{n}$ & $\%$ & $\mathbf{n}$ & $\%$ & \\
\hline Male sex & 310 & 60.7 & 25 & 56.8 & 335 & 60.4 & 0.633 \\
\hline \multicolumn{8}{|l|}{ Age group (years) } \\
\hline$\leq 28$ days & 160 & 31.3 & 11 & 25.0 & 171 & 30.8 & \\
\hline 29 days- 1 year & 79 & 15.4 & 6 & 13.6 & 85 & 15.3 & \\
\hline $1-9$ & 30 & 5.9 & 1 & 2.3 & 31 & 5.6 & \\
\hline $10-19$ & 18 & 3.5 & 1 & 2.3 & 19 & 3.4 & \\
\hline $20-29$ & 37 & 7.2 & 4 & 9.1 & 41 & 7.4 & \\
\hline $30-39$ & 52 & 10.2 & 7 & 15.9 & 59 & 10.6 & \\
\hline $40-49$ & 43 & 8.4 & 6 & 13.6 & 49 & 8.8 & \\
\hline $50-59$ & 47 & 9.2 & 6 & 13.6 & 53 & 9.5 & \\
\hline$\geq 60$ & 46 & 9.0 & 2 & 4.6 & 48 & 8.6 & 0.634 \\
\hline \multicolumn{8}{|l|}{ Province } \\
\hline Gauteng & 308 & 60.0 & 28 & 63.6 & 336 & 60.3 & \\
\hline Western Cape & 205 & 40.0 & 16 & 36.4 & 221 & 39.7 & 0.749 \\
\hline \multicolumn{8}{|l|}{ Clinical syndrome } \\
\hline Bacteraemia without focus & 291 & 63.0 & 28 & 63.6 & 319 & 63.0 & \\
\hline Joint infection & 6 & 1.3 & 0 & 0.0 & 6 & 1.2 & \\
\hline Pneumonia & 69 & 14.9 & 10 & 22.7 & 79 & 15.6 & \\
\hline Meningitis & 4 & 0.9 & 2 & 4.6 & 6 & 1.2 & \\
\hline Skin or soft tissue infection & 73 & 15.8 & 1 & 2.3 & 74 & 14.6 & \\
\hline Other & 19 & 4.1 & 3 & 6.8 & 22 & 4.4 & 0.017 \\
\hline \multicolumn{8}{|l|}{ Mental status/ GCS } \\
\hline GCS 15 / Alert & 119 & 22.8 & 16 & 69.6 & 135 & 76.7 & \\
\hline GCS 13-14 / Disorientated & 18 & 11.8 & 4 & 17.4 & 22 & 12.5 & \\
\hline GCS 9-12 / Stuporous & 8 & 5.2 & 1 & 4.4 & 9 & 5.1 & \\
\hline GCS 3-8 / Coma & 8 & 5.2 & 2 & 8.7 & 10 & 5.7 & 0.628 \\
\hline \multicolumn{8}{|l|}{ In-hospital outcome } \\
\hline Survived & 261 & 58.5 & 27 & 61.4 & 288 & 58.8 & \\
\hline Died & 185 & 41.5 & 17 & 38.6 & 202 & 41.2 & 0.751 \\
\hline \multicolumn{8}{|l|}{ Predisposing factors } \\
\hline Prior MRSA infection & 27 & 6.0 & 1 & 2.3 & 28 & 5.7 & 0.497 \\
\hline Prior dialysis & 16 & 3.5 & 0 & 0.0 & 16 & 3.2 & 0.382 \\
\hline Prior surgery & 133 & 29.0 & 1 & 2.3 & 134 & 26.7 & $<0.001$ \\
\hline $\begin{array}{l}\text { Resident in a long-term care } \\
\text { facility }\end{array}$ & 22 & 4.8 & 0 & 0.0 & 22 & 4.4 & 0.242 \\
\hline HIV-infection & 65 & 25.2 & 10 & 52.6 & 75 & 27.1 & 0.015 \\
\hline Pre-existing conditions§ & 28 & 6.7 & 1 & 3.6 & 29 & 6.5 & 1.000 \\
\hline
\end{tabular}

$\S$ Pre-existing conditions include pulmonary, cardiac, renal, hepatic, neurological conditions, head injury, anaemia, connective tissue disorders, diabetes mellitus, primary immune disorders, alcohol use, smoking, prematurity, burns, malnutrition and malignancy

\# Denominators vary owing to missing data

$\infty$ GSC-Glasgow Coma Score 
Demographic and clinical characteristics of cases with emphasize on CA and HA MRSA

Among all patients with MRSA infection, $60.4 \%$ were male (335/555) (Table 1). The median age of all patients with MRSA infection was 3 years (interquartile range (IQR): 0.05-42.44). The majority of both CA-MRSA and HA-MRSA cases with age data available were <1 year of age [CA-MRSA: 17/44 (38.6\%); HA-MRSA: $239 / 512$ (46.7\%)], with most cases $\leq 28$ days [CA-MRSA: 11/44 (25\%); HA-MRSA: 160/512 (31.3\%)]. Among cases with CA-MRSA, almost $16 \%$ were aged $30-39$ years, but only $4.6 \%$ of cases were aged $\geq 60$ years or older. Among cases of HA-MRSA, $10.2 \%$ were aged $30-39$ and $9 \% \geq 60$ years (Table 1 and Figure 2). The ratio of CA-MRSA to HA-MRSA cases was similar for Gauteng and Western Cape provinces $(\mathrm{p}=0.75)$. Bacteraemia without a known focus was the most common clinical syndrome in both CA-MRSA (28/44, 63.6\%) and HA-MRSA cases (291/462, 63\%). Pneumonia accounted for $22.7 \%$ among CA-MRSA (10/44) versus 14.9\% among HA-MRSA (69/462) cases. Among 277 cases with known HIV-infection status, 10 of 19 case patients with CA-MRSA were HIVinfected (52.6\%), compared to 65 of $258(25.2 \%)$ among those with HA-MRSA infection $(\mathrm{p}=0.015)$. The ratio of MRSA cases to MSSA cases increased from 27\% (59/216) in 2013 to 32\% (242/748) in 2015 but this was not a significant change $(\mathrm{p}=0.37)$. Additionally, the ratio of CA-MRSA to HA-MRSA cases did not change significantly over the three-year period $(\mathrm{p}=0.29)$.

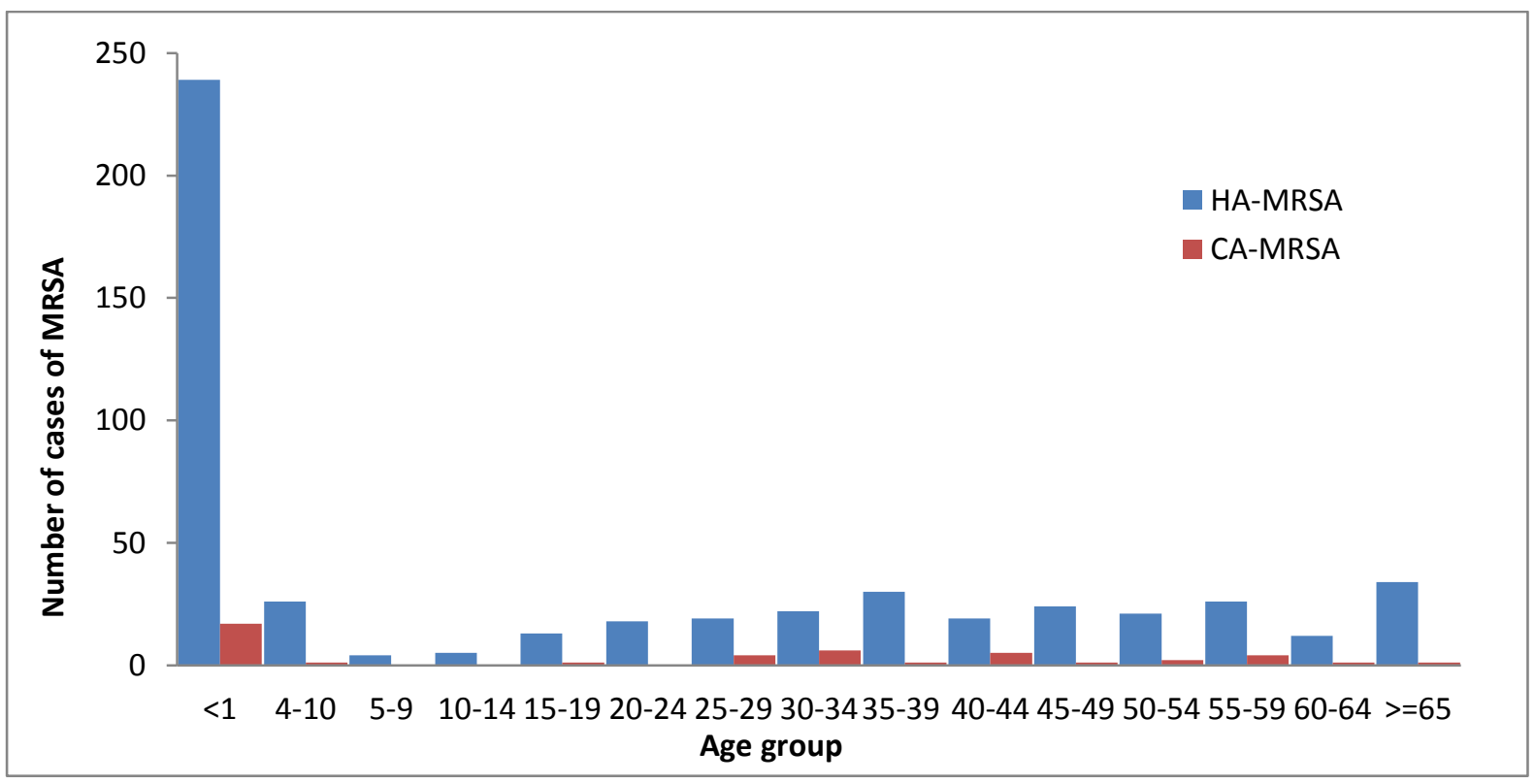

Figure 2: Distribution of cases of methicillin-resistant Staphylococcus aureus (MRSA) bacteraemia by age group at five sentinel hospitals, South Africa, January 2013 to January 2016. HA-MRSA = Hospitalassociated methicillin-resistant Staphylococcus aureus; CA-MRSA = Community-associated methicillin-resistant Staphylococcus aureus 
Antimicrobial susceptibility results for all S. aureus isolates

All S. aureus blood culture isolates demonstrated significantly reduced susceptibility to the following classes of antimicrobial agents: $\beta$ - lactams, macrolides, tetracyclines, aminoglycosides, and cotrimoxazole, in 2015 compared to 2013 ( $\mathrm{p}<0.05$ ) but not compared to 2013 (Figure 3). The $\mathrm{MIC}_{50}$ and $\mathrm{MIC}_{90}$ values of all antimicrobials were unchanged over the three-year period (Table 2). Figure 4 compares susceptibilities to antimicrobial agents and these were not significantly different for HA-MRSA versus CA-MRSA isolates, except for a higher proportion of HA-MRSA isolates resistant to rifampicin. We recorded 72 isolates with vancomycin MIC of 2; 17 patients died including 10 with MRSA and 48 recovered including 38 patients with MRSA; majority had SCCmec type III.

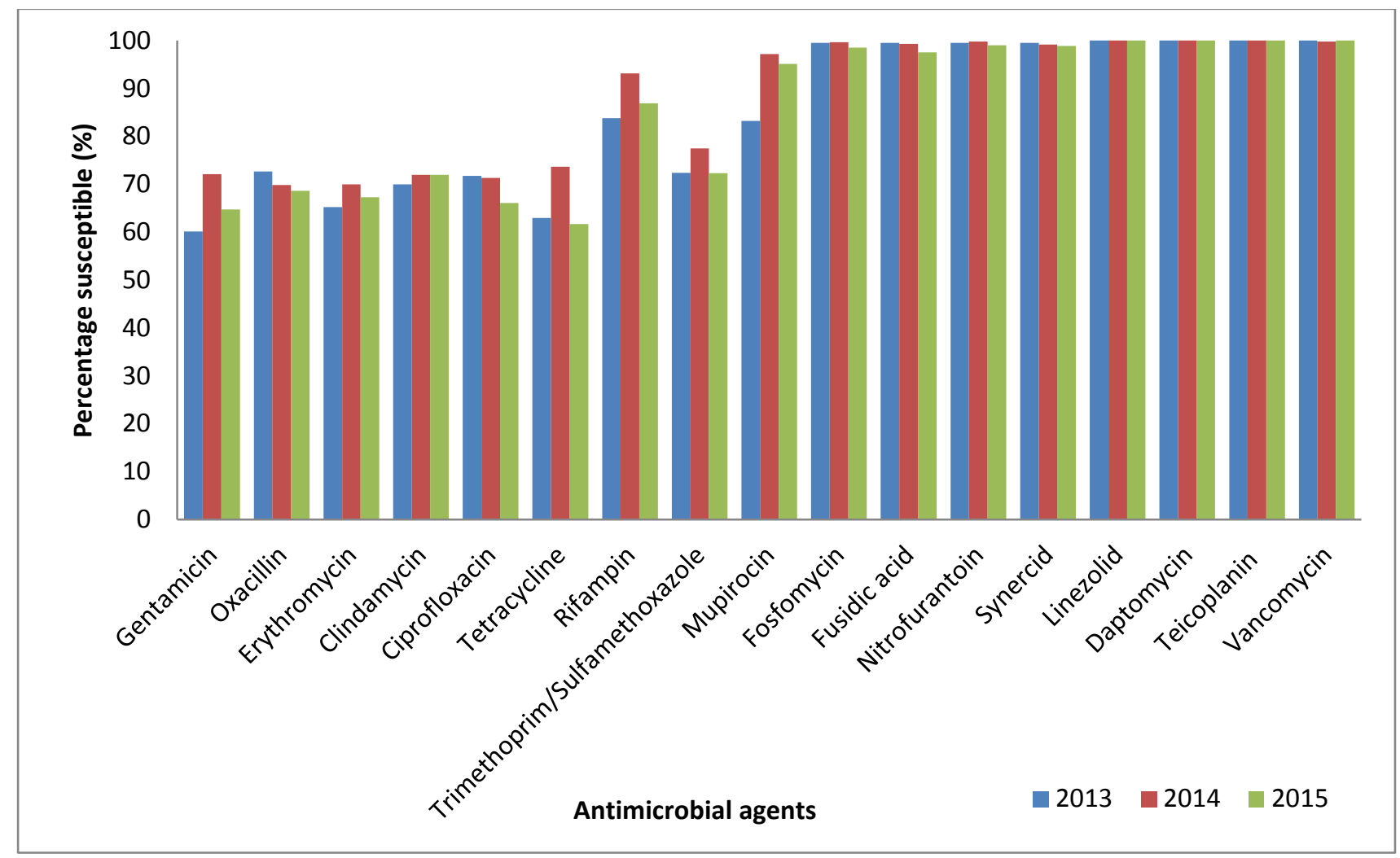

Figure 3: Antimicrobial susceptibility testing results for 1623 isolates from surveillance sites for 2013 to 
Table 2: $\mathrm{MIC}_{50}$ and $\mathrm{MIC}_{90}$ on $1623 \mathrm{~S}$. aureus isolates from surveillance sites

\begin{tabular}{|c|c|c|c|c|c|c|}
\hline \multirow[t]{2}{*}{ Antibiotics } & \multicolumn{2}{|l|}{2013} & \multicolumn{2}{|l|}{2014} & \multicolumn{2}{|l|}{2015} \\
\hline & MIC50 & MIC90 & MIC50 & MIC90 & MIC50 & MIC90 \\
\hline Gentamicin & $\leq 4$ & $>8$ & $\leq 1$ & 8 & $\leq 1$ & $>8$ \\
\hline Oxacillin & $\leq 0.25$ & $\leq 0.25$ & $\leq 0.25$ & $\leq 0.25$ & $\leq 0.25$ & $\leq 0.25$ \\
\hline Erythromycin & $\leq 0.5$ & $>4$ & $\leq 0.5$ & $>4$ & $\leq 0.5$ & $>4$ \\
\hline Clindamycin & $\leq 0.25$ & $\leq 0.25$ & $\leq 0.25$ & $\leq 0.25$ & $\leq 0.25$ & $\leq 0.25$ \\
\hline Ciprofloxacin & $\leq 0.5$ & $>2$ & $\leq 0.5$ & $>2$ & $\leq 0.5$ & $>2$ \\
\hline Tetracycline & $\leq 4$ & $>8$ & $\leq 4$ & $>8$ & $\leq 4$ & $>8$ \\
\hline Rifampin & $\leq 1$ & $>2$ & $\leq 0.5$ & $\leq 1$ & $\leq 0.5$ & $>2$ \\
\hline Trimethoprim/Sulfamethoxazole & $\leq 2 / 38$ & $>4 / 76$ & $\leq 2 / 38$ & $>4 / 76$ & $\leq 2 / 38$ & $>4 / 76$ \\
\hline Mupirocin & $\leq 256$ & $\leq 256$ & $\leq 256$ & $\leq 256$ & $\leq 256$ & $\leq 256$ \\
\hline Fosfomycin & $\leq 32$ & $\leq 32$ & $\leq 32$ & $\leq 32$ & $\leq 32$ & $\leq 32$ \\
\hline Fusidic acid & $\leq 2$ & $\leq 2$ & $\leq 2$ & $\leq 2$ & $\leq 2$ & $\leq 2$ \\
\hline Nitrofurantoin & $\leq 32$ & $\leq 32$ & $\leq 32$ & $\leq 32$ & $\leq 32$ & $\leq 32$ \\
\hline Quinupristin-dalfopristin & $\leq 1$ & $\leq 1$ & $\leq 1$ & $\leq 1$ & $\leq 1$ & $\leq 1$ \\
\hline Linezolid & $\leq 2$ & $\leq 2$ & $\leq 2$ & $\leq 2$ & $\leq 2$ & $\leq 2$ \\
\hline Daptomycin & $\leq 1$ & $\leq 1$ & $\leq 1$ & $\leq 1$ & $\leq 1$ & $\leq 1$ \\
\hline Teicoplanin & $\leq 1$ & $\leq 1$ & $\leq 1$ & $\leq 1$ & $\leq 1$ & $\leq 1$ \\
\hline Vancomycin & 1 & 1 & 1 & 1 & 1 & 1 \\
\hline
\end{tabular}

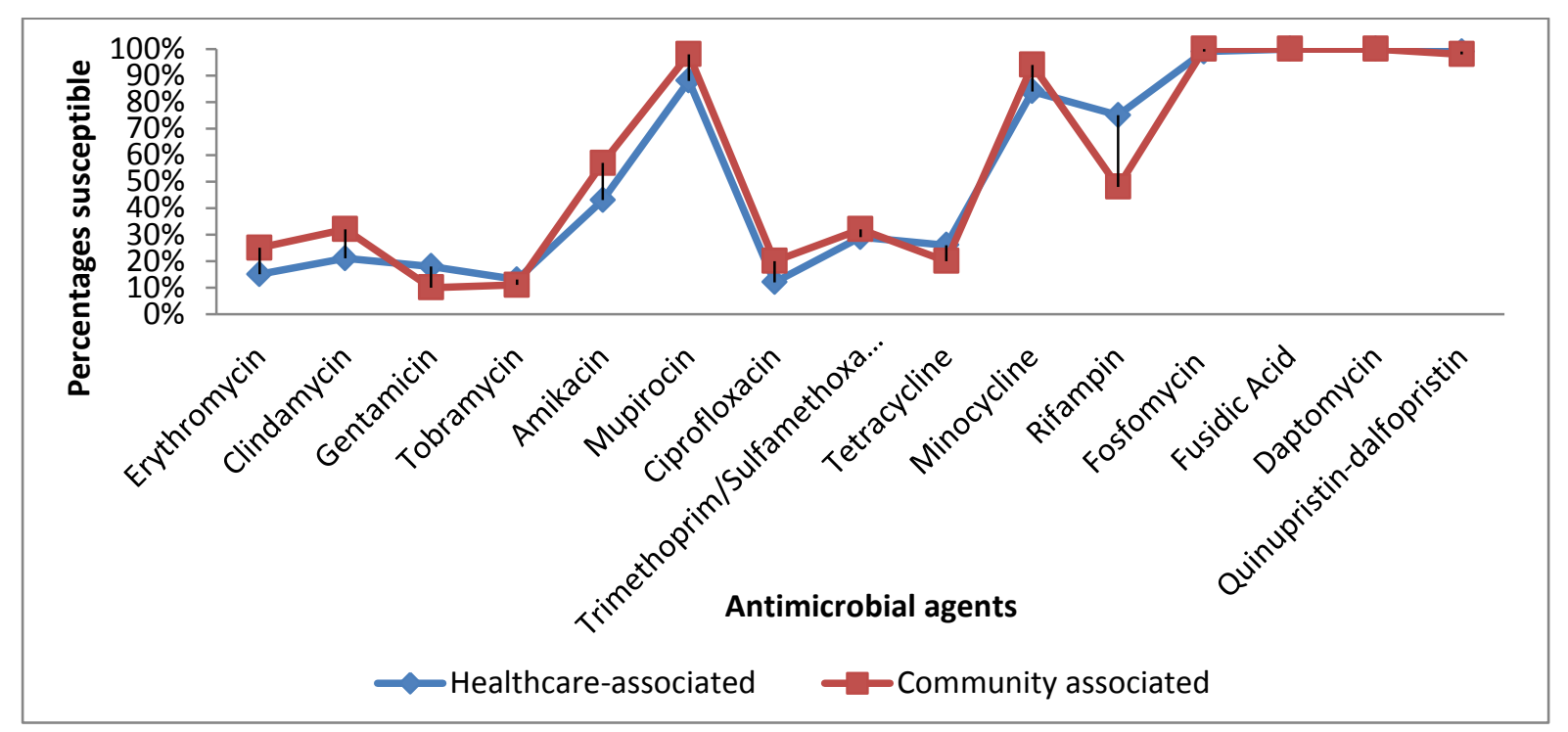

Figure 4: Antimicrobial susceptibility patterns of 557 MRSA isolates stratified by hospital or community origin

PCR screening for mecA and mecC in MRSA isolates

We analysed the available 484 isolates resistant to oxacillin and confirmed mecA in 483, except one MRSA isolate was negative for both mecA and mecC. 


\section{SCCmec typing}

Of the 557 MRSA isolates, 484 (87\%) were typed: the most common SCCmec type was SCCmec type III ( $\mathrm{n}=236$, $48.76 \%)$ followed by types IV ( $\mathrm{n}=144,29.76 \%), \mathrm{II}(\mathrm{n}=42,8.68 \%), \mathrm{VI}(\mathrm{n}=4,0.83 \%), \mathrm{V}(\mathrm{n}=3,0.62 \%)$ and type I $(\mathrm{n}=1,0.21 \%)$; the rest of isolates could not be typed (Figure 5. Unknown typing patterns were identified for 52 isolates $(10.74 \%)$. Multiple banding patterns were observed and require further investigation. Two isolates produced no amplicons and therefore no resultant SCCmec type. Overall, SCCmec typing results showed a difference between the two provinces; a predominance of type III ( $n=206 / 484,43 \%)$ was observed in Gauteng and a predominance of type IV $(\mathrm{n}=77 / 484,16 \%)$ was seen in the Western Cape. Among the type IV isolates, the majority were of hospital origin unexpectedly and showed the similar susceptibility to classes of antibiotics other than the $\beta$-lactams (Figures 4 and 5).

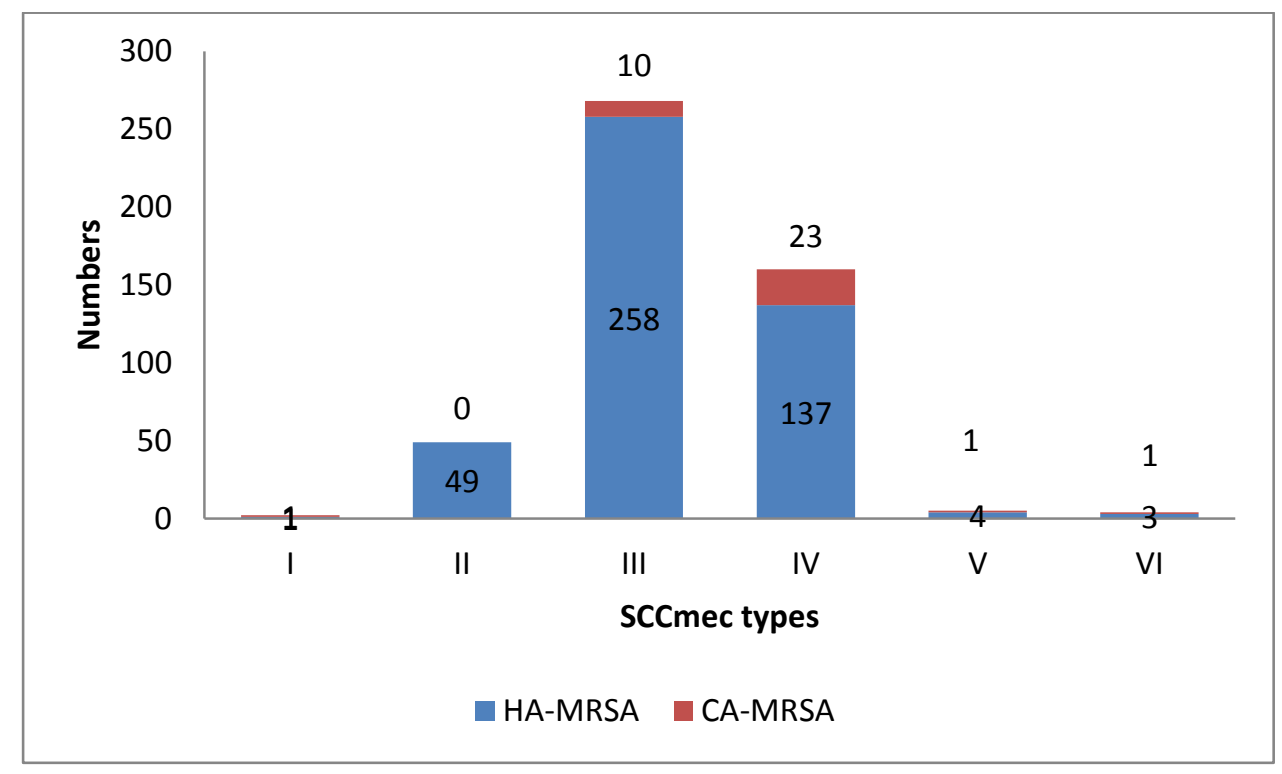

Figure 5: Distribution of 484 SCCmec types among HA and CA MRSA

Spa-typing

Spa-typing of 484 oxacillin resistant isolates revealed 49 different spa-types, 15 of which were novel and have not as yet been assigned. Two isolates could not be typed. The five most common spa-types were t037 ( $\mathrm{n}=229$, 47.31\%), t1257 (n=90, 18.60\%), t045 (n=44, 9.09\%), t012 (n=32, 6.61\%) and t064 (n=10, 2.07\%) which accounted for $84 \%$ of the isolates tested. The majority ( $\mathrm{n}=214,44.21 \%$ ) of the SCCmec type III isolates belonged to spa-type t037; the majority ( $\mathrm{n}=80,16.53 \%)$ of the SCCmec type IV isolates belonged to spa-type t1257 and the majority ( $\mathrm{n}=27,5.58 \%)$ of the SCCmec type II isolates belonged to $s p a$-type t012. The majority $(\mathrm{n}=35,7.23 \%)$ of 
the unknown SCCmec type isolates belonged to spa-type t045. SCCmec types I, V and VI accounted for only a few isolates. Spa-CC-064 (17\% of all spa-types) was the largest clonal complex followed by spa-CC-012 (15\% of all spa-types) and spa-CC-032/022 (9\% of all spa-types). Spa-CC-064 contained isolates displaying predominantly the SCCmec type IV element. Spa-CC-037 contained isolates that displayed predominantly SCCmec types III as well as types II, IV and unknown typing patterns (Table 4). Spa-CC-064 and spa-CC-037 were identified in both Gauteng and the Western Cape $(6,7)$. Table 3 shows the six most common spa-types and correlating SCCmec types for hospital- and community-associated infections. All six spa-types and all represented SCCmec types were observed for hospital-associated infections. For community-associated infections, SCCmec type III-spa-type t037 was observed for nine isolates; SCCmec type IV-spa-type t1257 was observed in 13 isolates and SCCmec type IV-spa-type t064 and -t032 was observed in one isolate each.

Table 3: SCCmec types and spa types observed for Hospital-associated and Community-associated Infections

\begin{tabular}{|l|llll|llllllllllll|l|l|l|}
\hline & \multicolumn{3}{|c}{ II } & & III & & & & & IV & & & & & V \\
& $\mathrm{t} 037$ & $\mathrm{t} 1257$ & $\mathrm{t} 012$ & $\mathrm{t} 064$ & $\mathrm{t} 037$ & $\mathrm{t} 1257$ & $\mathrm{t} 012$ & $\mathrm{t} 045$ & $\mathrm{t} 032$ & $\mathrm{t} 037$ & $\mathrm{t} 1257$ & $\mathrm{t} 012$ & $\mathrm{t} 064$ & $\mathrm{t} 032$ & $\mathrm{t} 045$ & Total \\
\hline HA & 4 & 2 & 28 & 1 & 227 & 6 & 3 & 7 & 1 & 8 & 71 & 1 & 8 & 7 & 3 & 377 \\
CA & & & & & 9 & & & & & & 13 & & 1 & 1 & & 24 \\
\hline
\end{tabular}

Those representing the 6 most common spa types overall are included in this table. Untypable SCCmec types were excluded from this analysis.

HA: Hospital-associated infection

CA: Community-associated infection

\section{Multilocus sequence typing (MLST)}

The most common STs observed were ST239 and ST612 both belonging to the clonal complex 8 (CC8) (n=8 each followed by ST612 (CC8) (n=5, ST36 (CC30) and ST5 (CC5) (n=4 each) and ST22 (CC22) (n=3) One isolate produced a novel ST (ST4121). The allelic profile was very similar to 13 existing STs on the MLST database but differed by one allele (aroe). The 13 STs included the following: ST22, 44, 854, 927, 928, 970, 1037, 1645, 2037, 2892, 2893, 2894, 3211. The isolates and their corresponding SCCmec types, spa-types, sequence types (ST) and clonal complexes (CC) can be seen in Table 4 . 


\begin{tabular}{|c|c|c|c|c|c|c|}
\hline Sample ID & SCCmec type & Spa-type & ST & $\mathrm{CC}$ & Type of infection & Year \\
\hline 7775 & IV & t064 & 612 & 8 & $\mathrm{HA}$ & 2013 \\
\hline 8307 & II & t012 & 36 & 30 & HA & 2014 \\
\hline 8538 & IV & t012 & 22 & 22 & HA & 2014 \\
\hline 8544 & III & t012 & 612 & 8 & HA & 2014 \\
\hline 8204 & Unknown & t037 & 239 & 8 & HA & 2014 \\
\hline 8203 & III & t037 & 239 & 8 & HA & 2014 \\
\hline 8371 & IV & t037 & 239 & 8 & HA & 2014 \\
\hline 8401 & II & t037 & 36 & 30 & HA & 2014 \\
\hline 8366 & III & t045 & 36 & 30 & HA & 2014 \\
\hline 8325 & II & t064 & 36 & 30 & HA & 2014 \\
\hline 8451 & IV & t064 & 612 & 8 & HA & 2014 \\
\hline 8534 & IV & t064 & 612 & 8 & HA & 2014 \\
\hline 8362 & II & $\mathrm{t} 1257$ & 239 & 8 & HA & 2014 \\
\hline 8398 & III & $\mathrm{t} 1257$ & 239 & 8 & HA & 2014 \\
\hline 8462 & IV & $\mathrm{t} 1257$ & 612 & 8 & HA & 2014 \\
\hline 9518 & III & t012 & 239 & 8 & HA & 2015 \\
\hline 9843 & IV & $\mathrm{t} 032$ & 22 & 22 & HA & 2015 \\
\hline 9210 & IV & $\mathrm{t} 032$ & 4121 & Not assigned & HA & 2015 \\
\hline 9192 & V & t045 & 5 & 5 & HA & 2015 \\
\hline 9335 & $\mathrm{~V}$ & $\mathrm{t} 045$ & 5 & 5 & HA & 2015 \\
\hline 9336 & Unknown & t045 & 5 & 5 & HA & 2015 \\
\hline 9509 & Unknown & $\mathrm{t} 1257$ & 5 & 5 & HA & 2015 \\
\hline 7730 & IV & t064 & 612 & 8 & $\mathrm{CA}$ & 2013 \\
\hline 8243 & III & t037 & 239 & 8 & $\mathrm{CA}$ & 2014 \\
\hline 9588 & IV & t032 & 22 & 22 & CA & 2015 \\
\hline 8853 & III & t037 & 239 & 8 & $\mathrm{CA}$ & 2015 \\
\hline 9018 & IV & $\mathrm{t} 1257$ & 612 & 8 & $\mathrm{CA}$ & 2015 \\
\hline 9316 & IV & $\mathrm{t} 1257$ & 612 & 8 & $\mathrm{CA}$ & 2015 \\
\hline
\end{tabular}

HA: Hospital-associated infection

CA: Community-associated infection

* novel ST. ST similar to the following 13 STs on the MLST database (http://saureus.beta.mlst.net/), however the aroe allele differed: ST22, 44, 854, 927, 928, 970, 1037, 1645, 2037, 2892, 2893, 2894, 3211. The CC is not assigned.

\section{Predisposing factors and clinical outcome}

Among all patients with MRSA infection, HIV-infected patients were three times more likely to have CA-MRSA than HA-MRSA, after adjustment for age and sex (aOR: 3.3; 95\% CI: 1.1-9.3). Fever (body temperature $\geq 37.5^{\circ} \mathrm{C}$ ) at diagnosis of bacteraemia was associated with HA-MRSA (aOR: 0.2; 95\% CI: 0.05-0.7) rather than CA-MRSA, while other underlying conditions such as diabetes mellitus and kidney disease were not associated with CAMRSA (Table 4). Crude in-hospital mortality was 41.2\% among 490 MRSA cases with known clinical outcome. Seventeen of 44 cases with CA-MRSA died (38.6\%), compared to 41.5\% of cases with HA-MRSA (185/446). 
There was no clear association between the type of MRSA infection (CA-MRSA or HA-MRSA) and clinical outcome. However, increasing age, having suffered cardiac arrest on the day of specimen collection (aOR: 23.03; 95\% CI: 2.88-183.93), being mechanically ventilated at the time of specimen collection (aOR: $1.89 ; 95 \%$ CI: 1.21-2.95), and prior MRSA infection (aOR: 3.44; 95\% CI: 1.38-8.53) were significantly associated with mortality among patients with MRSA infection (Table 5).

Table 5: Univariate and multivariable logistic regression analysis of predisposing factors associated with CA-MRSA and HA-MRSA bacteraemia

\begin{tabular}{|c|c|c|c|c|c|c|}
\hline \multirow[t]{2}{*}{ Characteristics } & \multirow{2}{*}{$\begin{array}{l}\text { CA-MRSA } \\
(\mathrm{n}=44) \\
\mathrm{n} / \mathrm{N}(\%)\end{array}$} & \multirow{2}{*}{$\begin{array}{l}\text { HA-MRSA } \\
(\mathbf{n}=\mathbf{5 1 3}) \\
\mathbf{n} / \mathbf{N}(\%)\end{array}$} & \multicolumn{2}{|c|}{ Univariate analysis } & \multicolumn{2}{|c|}{ Multivariable } \\
\hline & & & OR $(95 \% \mathrm{CI})$ & p-value & $\begin{array}{l}\text { aOR }(95 \% \\
\text { CI })\end{array}$ & p-value \\
\hline \multicolumn{7}{|l|}{ Sex } \\
\hline Male & $25 / 44(56.8)$ & $310 / 511(60.7)$ & reference & & reference & \\
\hline Female & $19 / 44(43.2)$ & $201 / 511(39.3)$ & $1.17(0.6-2.2)$ & 0.617 & $1.3(0.4-3.6)$ & 0.605 \\
\hline \multicolumn{7}{|l|}{ Age } \\
\hline $\begin{array}{l}\text { Median age in } \\
\text { years (IQR) }\end{array}$ & $\begin{array}{l}26.5(0.09- \\
42.8)\end{array}$ & $2.4(0.05-42.3)$ & $1.0(0.99-1.01)$ & 0.414 & $1.0(0.9-1.0)$ & 0.409 \\
\hline \multicolumn{7}{|l|}{ Province } \\
\hline Gauteng & $28 / 44(63.6)$ & $308 / 513(60.0)$ & reference & & & \\
\hline Western Cape & $16 / 44(36.4)$ & $205 / 513(40)$. & $0.85(0.4-1.63)$ & 0.64 & & \\
\hline \multicolumn{7}{|l|}{$\begin{array}{l}\text { Clinical } \\
\text { syndrome* }\end{array}$} \\
\hline Bacteraemia & $28 / 44(63.6)$ & $291 / 462(63.0)$ & reference & & & \\
\hline Joint infection & $0 / 44(0)$ & $6 / 462(1.3)$ & 1 & - & & \\
\hline Pneumonia & $10 / 44(22.7)$ & $69 / 462(14.9)$ & $1.5(0.6-3.3)$ & 0.296 & & \\
\hline Meningitis & $2 / 44(4.6)$ & $4 / 462(0.9)$ & $5.2(0.9-29.7)$ & 0.064 & & \\
\hline $\begin{array}{l}\text { Skin or soft tissue } \\
\text { infection }\end{array}$ & $1 / 44(2.3)$ & $73 / 462(15.8)$ & $0.1(0.01-1.1)$ & 0.057 & & \\
\hline Other & $3 / 44(6.8)$ & $19 / 462(4.1)$ & $1.6(0.4-5.9)$ & 0.447 & & \\
\hline \multicolumn{7}{|l|}{ Clinical signs } \\
\hline \multicolumn{7}{|l|}{$\begin{array}{l}\text { Fever at diagnosis } \\
(\text { temperature } \\
\left.\geq 37.5^{\circ} \mathrm{C}\right)\end{array}$} \\
\hline No & $33 / 43(76.7)$ & $250 / 416(60.1)$ & reference & & reference & \\
\hline Yes & $10 / 43(23.3)$ & $166 / 416(39.9)$ & $0.46(0.21-0.96)$ & 0.036 & $\begin{array}{l}0.19(0.05- \\
0.70)\end{array}$ & 0.012 \\
\hline \multicolumn{7}{|l|}{$\begin{array}{l}\text { Mental status/ } \\
\text { GCS }\end{array}$} \\
\hline GCS 15 / Alert & $16 / 23(69.6)$ & $119 / 153(77.8)$ & reference & & & \\
\hline GCS 13-14 / & $4 / 23(17.4)$ & $18 / 153(11.8)$ & $1.7(0.4-5.6)$ & 0.413 & & \\
\hline Disorientated & & & & & & \\
\hline GCS 9-12 / & $1 / 23(4.4)$ & $8 / 153(5.2)$ & $0.93(0.10-7.93)$ & 0.947 & & \\
\hline Stuporous & & & & & & \\
\hline GCS 3-8 / Coma & $2 / 23(8.7)$ & $8 / 153(5.2)$ & $1.9(0.3-9.6)$ & 0.457 & & \\
\hline $\begin{array}{l}\text { Predisposing } \\
\text { factors } \\
\text { Participation in } \\
\text { contact sports }\end{array}$ & & & & & & \\
\hline No & $42 / 42(100)$ & $445 / 451(98.7)$ & reference & & & \\
\hline Yes & $0 / 42(0)$ & $6 / 451(1.3)$ & 1 & - & & \\
\hline $\begin{array}{l}\text { Living or working } \\
\text { in crowded } \\
\text { facilities }\end{array}$ & & & & & & \\
\hline
\end{tabular}




\begin{tabular}{|c|c|c|c|c|c|c|}
\hline No & $40 / 42(95.2)$ & $427 / 449(95.1)$ & reference & & & \\
\hline Yes & $2 / 42(4.8)$ & $22 / 449(4.9)$ & $0.97(0.22-4.28)$ & 0.968 & & \\
\hline \multicolumn{7}{|c|}{$\begin{array}{l}\text { Prior MRSA } \\
\text { infection }\end{array}$} \\
\hline No & 43/44 (97.7) & $425 / 452(94.0)$ & reference & & & \\
\hline Yes & $1 / 44(2.3)$ & $27 / 452(6.0)$ & $0.37(0.04-2.77)$ & 0.33 & & \\
\hline \multicolumn{7}{|c|}{ Prior dialysis } \\
\hline No & 44/44 (100) & $443 / 459(96.5)$ & reference & & & \\
\hline Yes & $0 / 44(0)$ & $16 / 459(3.5)$ & 1 & - & & \\
\hline \multicolumn{7}{|c|}{$\begin{array}{l}\text { Resident in a } \\
\text { long-term care } \\
\text { facility }\end{array}$} \\
\hline No & $42 / 42(100)$ & $433 / 455(95.2)$ & reference & & & \\
\hline Yes & $0 / 42(0)$ & $22 / 455(4.8)$ & 1 & - & & \\
\hline \multicolumn{7}{|c|}{$\begin{array}{l}\text { Pre-existing } \\
\text { conditions§ }\end{array}$} \\
\hline No & 9/19 (47.4) & $193 / 258(74.8)$ & reference & & reference & \\
\hline Yes & $10 / 19(52.6)$ & $65 / 258(25.2)$ & $3.3(1.2-8.5)$ & 0.013 & $3.3(1.1-9.3)$ & 0.026 \\
\hline \multicolumn{7}{|c|}{ Kidney disease } \\
\hline No & $22 / 28(78.6)$ & $385 / 416(92.6)$ & reference & & & \\
\hline Yes & $6 / 28(21.4)$ & $31 / 416(7.5)$ & $3.4(1.2-9.0)$ & 0.014 & & \\
\hline \multicolumn{7}{|c|}{ Diabetes mellitus } \\
\hline No & $23 / 28(82.1)$ & $386 / 416(92.8)$ & reference & & & \\
\hline Yes & $5 / 28(17.9)$ & $30 / 416(7.2)$ & $2.8(1.0-7.8)$ & 0.052 & & \\
\hline
\end{tabular}

Note: An odds ratio $(\mathrm{OR})>1$ suggests an association with CA-MRSA, while an $\mathrm{OR}<1$ suggests an association with HA-MRSA. Denominators differ due to missing data for certain variables

Table 6: Univariate and multivariable logistic regression analysis of factors associated with mortality among patients with CA-MRSA and HA-MRSA bacteraemia.

\begin{tabular}{|c|c|c|c|c|c|}
\hline \multirow[b]{2}{*}{ Characteristics } & \multirow{2}{*}{$\begin{array}{l}\begin{array}{l}\text { Died } \\
(n=202)\end{array} \\
\text { n/N }(\%)\end{array}$} & \multicolumn{2}{|c|}{ Univariate analysis } & \multicolumn{2}{|c|}{ Multivariable analysis } \\
\hline & & & $\begin{array}{l}\text { p- } \\
\text { value }\end{array}$ & aOR $(95 \%$ CI $)$ & p-value \\
\hline \multicolumn{6}{|l|}{ MRSA type } \\
\hline HA-MRSA & $185 / 446(41.5)$ & reference & & reference & \\
\hline CA-MRSA & $17 / 44$ (38.6) & $0.89(0.47-1.68)$ & 0.715 & $0.86(0.42-1.73)$ & 0.661 \\
\hline \multicolumn{6}{|l|}{ Sex } \\
\hline Male & $118 / 290(40.7)$ & reference & & & \\
\hline Female & $83 / 199(41.7)$ & $1.04(0.72-1.50)$ & 0.822 & & \\
\hline \multicolumn{6}{|l|}{ Age group (years) } \\
\hline$<1$ & $72 / 230(31.3)$ & reference & & reference & \\
\hline $1-9$ & $9 / 28(32.1)$ & $1.04(0.44-2.41)$ & 0.928 & $0.88(0.33-2.33)$ & 0.793 \\
\hline $10-19$ & $6 / 13(46.2)$ & $1.88(0.61-5.80)$ & 0.271 & $2.1(0.66-6.60)$ & 0.204 \\
\hline $20-29$ & $11 / 34(32.4)$ & $1.05(0.48-2.27)$ & 0.902 & $1.09(0.48-2.46)$ & 0.833 \\
\hline $30-39$ & $25 / 53(47.2)$ & $1.96(1.06-3.60)$ & 0.03 & $1.97(1.02-3.81)$ & 0.043 \\
\hline $40-49$ & $19 / 37(51.4)$ & $2.32(1.14-4.68)$ & 0.019 & $2.53(1.21-5.29)$ & 0.013 \\
\hline $50-59$ & $29 / 49(59.2)$ & $3.18(1.68-6.0)$ & $<0.001$ & $3.14(1.61-6.13)$ & 0.001 \\
\hline$\geq 60$ & $30 / 45(66.7)$ & $4.39(2.22-8.66)$ & $<0.001$ & $5.15(2.50-10.60)$ & $<0.001$ \\
\hline Province & & & & & \\
\hline
\end{tabular}




\begin{tabular}{|c|c|c|c|c|c|}
\hline Gauteng & $125 / 297(42.1)$ & reference & & & \\
\hline Western Cape & 77/193 (39.9) & $0.91(0.63-1.32)$ & 0.63 & & \\
\hline \multicolumn{6}{|l|}{ Clinical diagnosis } \\
\hline Bacteraemia & $126 / 311(40.5)$ & reference & & & \\
\hline Joint infection & $1 / 6(16.7)$ & $0.29(0.03-2.55)$ & 0.266 & & \\
\hline Pneumonia & $34 / 78(43.6)$ & $1.13(0.68-1.88)$ & 0.622 & & \\
\hline $\begin{array}{l}\text { Meningitis } \\
\text { Skin or soft tissue }\end{array}$ & $3 / 5(60)$ & $2.20(0.36-13.37)$ & 0.391 & & \\
\hline infection & 26/68 (38.2) & $0.91(0.53-1.56)$ & 0.728 & & \\
\hline Other & $12 / 21(57.1)$ & $1.96(0.80-4.79)$ & 0.141 & & \\
\hline \multicolumn{6}{|l|}{ Cardiac arrest } \\
\hline No & $185 / 472(39.2)$ & reference & & reference & \\
\hline Yes & $13 / 14(92.9)$ & $\begin{array}{l}20.17(2.61- \\
155.47)\end{array}$ & 0.004 & $\begin{array}{l}23.03(2.88- \\
183.93)\end{array}$ & 0.003 \\
\hline \multicolumn{6}{|l|}{ Mechanical ventilation } \\
\hline No & $134 / 352(38.1)$ & reference & & reference & \\
\hline Yes & $64.131(48.9)$ & $1.55(1.03-2.33)$ & 0.033 & $1.89(1.21-2.95)$ & 0.005 \\
\hline \multicolumn{6}{|l|}{ Clinical signs } \\
\hline \multicolumn{6}{|l|}{ Mental status/ GCS } \\
\hline $\begin{array}{l}\text { GCS 15 / Alert } \\
\text { GCS 13-14 / }\end{array}$ & $52 / 132(39.4)$ & reference & & & \\
\hline Disorientated & $12 / 21(57.1)$ & $2.1(0.80-5.22)$ & 0.131 & & \\
\hline GCS 9-12 / Stuporous & $5 / 9(55.6)$ & $1.92(0.49-7.50)$ & 0.346 & & \\
\hline $\begin{array}{l}\text { GCS 3-8 / Coma } \\
\text { Temperature at } \\
\text { diagnosis }\left({ }^{\circ} \mathbf{C}\right) \text { (median, } \\
\text { IQR) }\end{array}$ & $37(36.5-37.9)$ & $3.59(0.88-14.52)$ & 0.614 & & \\
\hline \multicolumn{6}{|l|}{ Predisposing factors } \\
\hline \multicolumn{6}{|l|}{ Prior MRSA infection } \\
\hline No & $178 / 455(39.1)$ & reference & & reference & \\
\hline Yes & $17 / 25(68.0)$ & $3.31(1.39-7.83)$ & 0.006 & $3.44(1.38-8.53)$ & 0.008 \\
\hline \multicolumn{6}{|l|}{ Prior dialysis } \\
\hline No & $191 / 470(40.6)$ & reference & & & \\
\hline Yes & $7 / 15(46.7)$ & $1.28(0.45-3.59)$ & 0.641 & & \\
\hline \multicolumn{6}{|l|}{ Prior surgery } \\
\hline No & $139 / 356(39.0)$ & reference & & & \\
\hline \multicolumn{6}{|l|}{$\begin{array}{l}\text { Resident in a long-term } \\
\text { care facility }\end{array}$} \\
\hline No & $181 / 459(39.4)$ & reference & & & \\
\hline Yes & $13 / 21(61.9)$ & $2.50(1.01-6.14)$ & 0.046 & & \\
\hline \multicolumn{6}{|l|}{ Pre-existing conditions } \\
\hline No & $30 / 60(50)$ & reference & & & \\
\hline Yes & $172 / 429(40.1)$ & $0.67(0.38-1.15)$ & 0.146 & & \\
\hline \multicolumn{6}{|l|}{ HIV infection } \\
\hline No & 79/196 (40.3) & reference & & & \\
\hline Yes & $33 / 70(47.1)$ & $1.3(0.7-2.3)$ & 0.321 & & \\
\hline
\end{tabular}

Note: denominators differ due to missing data for certain variables 


\section{Discussion}

To our knowledge, this is one of the largest epidemiological studies to describe $S$. aureus bacteraemia in South Africa; we analysed data from 1914 patients and compared cases of HA-MRSA and CA-MRSA infection. Overall, among cases of S. aureus bacteraemia, more than a quarter were due to MRSA, of which only $8 \%$ were categorised as CA-MRSA. This prevalence estimate is much lower than reported from studies in the United States, where the prevalence of CA-MRSA varied from $35 \%$ to $80 \%$ and suggests that the epidemiology of MRSA infection varies by region (5). Our findings might also differ from other regions due to different criteria used to define cases of CA-MRSA infection. In contrast to a recent review by Tong et al. and reports from sub-Saharan Africa and North America of cases among adults, most cases of bloodstream MRSA infection in South Africa were diagnosed among infants and young children in Gauteng province (42\%) but not in Western Cape (10\%) perhaps due to overcrowding in paediatric wards $(1,5,6)$.

The ratio of MRSA to MSSA cases was stable over the study period. The prevalence of S. aureus bacteraemia over the three-year study period was also largely unchanged. This is different to the trend observed in the USA (2). In this study, we also showed no evidence of replacement of HA-MRSA strains with CA-MRSA, unlike in HICs, where a majority of MRSA infections now originate in the community (5). In the last few decades, the incidence of CA-MRSA has reportedly increased in HICs, while in contrast, South Africa's epidemiology with a high proportion of HA-MRSA infection is similar to that reported from African region, study from Soweto and southern Europe $(14,15)$. These variations may be explained by factors such as risk profile of hospitalised patients. We found no difference in the epidemiology of CA-MRSA in two provinces with relatively wellresourced healthcare systems.

Interestingly, we found a dominance of SCCmec types III in Gauteng and IV in the Western Cape. Type III in Gauteng province was associated mostly with spa type t037 and type IV with the spa type t1257. These were previously reported as dominant in these provinces (6). The spa-type CC 012 in these two provinces was similar to a study from Tygerberg Academic Hospital (16). When the six most common spa-types (t037, t1257, t012, t045, t064 and t032) and SCCmec types were correlated, SCCmec types II, III, IV and V and all six spa-types were linked to hospital-associated infections. SCCmec types III and IV and spa-types t037, t1257, t064 and t032 were observed in community-associated infections. It should be noted that the majority of our isolates were regarded as hospital-associated infections $(\mathrm{n}=513)$ according to the definition used. The remaining 44 isolates were community-associated infections. Regarding spa-types, we confirmed that the majority of t037 (47\%) and t1257 (17\%), belonged mostly to the MLST CC8 clonal complex unlikely in Breurec study where CC8 was the 
sporadic clone and majority belong to CC239 related to Brazilian/Hungarian clone (17). This was observed in isolates belonging to both HA- and CA-infections. Of the six isolates that were spa-type t037, one isolate was ST36 (CC30) as expected and the remaining five isolates belonged to ST239 (CC8). The latter is an unusual occurrence which may be supported by a previous 2016 study which has shown that genetic exchange and recombination can occur resulting in isolates exhibiting spa-types which are usually known from another core genome as indicated by MLST. $(18,19)$. One isolate produced a novel ST. The allelic profile for aroe differed when compared to all other existing MLST profiles and a new ST was assigned. The commonest sequence types identified in this MRSA study were ST5, ST36, ST612, ST239, with a predominance of SCCmec types III and IV. This is similar to the other parts of the world, such as Europe and Australia. Similar to other African countries, ST239 related to Brazilian/Hungarian clone was common in our hospital settings $(17,19)$. There was no difference in molecular characteristics between the hospital- and community-associated infection groups. Furthermore, no evolution of clonal types was observed from 2013 to 2015.

HIV-infected persons were more likely to have CA-MRSA than HA-MRSA. This association might be explained by overall increase in this group of incidence of $S$. aureus bacteraemia $(1,20)$. In addition, fever at diagnosis was associated with HA-MRSA. These predisposing factors could potentially be used to construct a clinical algorithm for predicting whether a patient has CA-MRSA or HA-MRSA infection. In this study we demonstrated that SCCmec type IV MRSA infections were common among patients in healthcare facilities which makes it difficult to establish clear and objective differences between CA-MRSA and HA-MRSA strains (2). The high crude inhospital mortality of patients with both CA-MRSA and HA-MRSA infection was not a surprising finding and risk factors for mortality identified in the multivariable analysis such as old age, heart conditions, patients on mechanical ventilation, previous MRSA infections, patients in long term care facilities are in keeping with previous studies $(20,21,22)$. No outcome difference was found between CA-MRSA versus HA-MRSA infections in our study like indicated in previous research where NICU patient characteristics were similar (23).

Regarding susceptibility pattern over the study period $S$. aureus did not reveal significant increase in antimicrobial resistance. There were non-significant differences of susceptibility to other antimicrobial agents between CA- and HA-MRSA. CA-MRSA isolates showed more susceptibility to erythromycin and clindamycin but not rifampin which may be related to use for treatment and prevention of tuberculosis (15). This finding is in keeping with reports of community-associated infections from the USA and Australia showing that CA-MRSA isolates were more susceptible to macrolides, aminoglycosides and fluoroquinolones (2). A study from Portugal showed a 
decrease in multidrug-resistance profile in MRSA over a 20-year period (15) and a meta-analysis by Matthew and Falagas et.al. (4) showed varied susceptibility to various antibiotics. In hospitalized South African paediatric patients with bacteraemia high prevalence of MRSA was found in HIV-infected children (20). We found no resistance to the following classes of antibiotics: glycopeptides, oxazolidines, quinupristin/dalfopristin and daptomycin in both groups.

Our study has a number of limitations. Firstly, the presence of SCCmec types IV, V and VI, as well as a nonmultidrug resistance (non-MDR) antimicrobial phenotype (isolates not resistant to two or more classes of non- $\beta$ lactam antibiotics) were considered for inclusion in the case definition. However, these criteria were not included in the final definition as the number of cases with all four criteria was too low. This may have resulted in misclassification of CA-MRSA cases as HA-MRSA. Secondly, the majority of our patients had bacteraemia with no origin, perhaps due to incomplete clinical data to indicate origin of bacteraemia. Another limitation of our study was the inclusion of only academic centres in urban areas. Therefore, the results may not be representative of all healthcare facilities in South Africa (24).

\section{Conclusions}

In conclusion, this study demonstrates that $S$. aureus bacteraemia is common in South African academic centres and HA-MRSA is still the dominant cause of MRSA bacteraemia. A small proportion of CA-MRSA cases were caused by a few sequence types. The dominance of SCCmec type III existed however presence of SCCmec type IV have become evident that this replacement is emerging in hospitals. We found no resistance to glycopeptides, oxazolidines, quinupristin/dalfopristin and daptomycin in both MSSA and MRSA. Our resistance profile of CAMRSA isolates suggests that the macrolide group of agents should be used with caution or should be directed by results from susceptibility testing for treatment of localized infections. We recommend continuous surveillance of S. aureus bacteraemia to monitor trends of MRSA.

Conflict of Interest: There is no conflict of interest from authors on this manuscript as no external funding was received for the surveillance of Staphylococcus aureus bacteraemia.

Ethics approval: This study was approved by the University of the Witwatersrand Human Research Ethics Committee (Medical),); clearance certificate number: M160667. 
Informed consent: Informed Consent Form (ICF) was given to each patient enrolled in the study with description of the procedure, confidentiality and declaration with signatures of participant, surveillance officer and witnesses.

\section{References:}

1. Tong SY, Davis JS, Eichenberger E, Holland TL, Fowler VG, Jr. 2015. Staphylococcus aureus infections: epidemiology, pathophysiology, clinical manifestations, and management. Clin Microbiol Rev 28:603-61.

2. David MZ, Daum RS. 2010. Community-associated methicillin-resistant Staphylococcus aureus: epidemiology and clinical consequences of an emerging epidemic. Clin Microbiol Rev 23:616-87.

3. David MZ, Cadilla A, Boyle-Vavra S, Daum RS. 2014. Replacement of HA-MRSA by CA-MRSA infections at an academic medical center in the midwestern United States, 2004-5 to 2008. PLoS One 9: e92760.

4. Falagas ME, Karageorgopoulos DE, Leptidis J, Korbila IP. 2013. MRSA in Africa: filling the global map of antimicrobial resistance. PLoS One 8: e68024.

5. David MZ, Daum RS, Bayer AS, Chambers HF, Fowler VG, Jr., Miller LG, Ostrowsky B, Baesa A, Boyle-Vavra S, Eells SJ, Garcia-Houchins S, Gialanella P, Macias-Gil R, Rude TH, Ruffin F, Sieth JJ, Volinski J, Spellberg B. 2014. Staphylococcus aureus bacteremia at 5 US academic medical centers, 2008-2011: significant geographic variation in community-onset infections. Clin Infect Dis 59:798-807.

6. Perovic O, Iyaloo S, Kularatne R, Lowman W, Bosman N, Wadula J, Seetharam S, Duse A, Mbelle N, Bamford C, Dawood H, Mahabeer Y, Bhola P, Abrahams S, Singh-Moodley A. 2015. Prevalence and Trends of Staphylococcus aureus Bacteraemia in Hospitalized Patients in South Africa, 2010 to 2012: Laboratory-Based Surveillance Mapping of Antimicrobial Resistance and Molecular Epidemiology. PLoS One 10: e0145429.

7. Clinical and Laboratory Standards Institute (CLSI). 2017 M100 Performance Standards for Antimicrobial Susceptibility Testing $27^{\text {th }}$ Edition M02-A12, M07-A10, and M11-A8.

8. European Committee on Antimicrobial Susceptibility Testing Breakpoint tables for interpretation of MICs and zone diameters Version 7.1, valid from 2017-03-10

9. Thomas, C.L. et al. (2007). Development of real-time Staphylococcus aureus and MRSA (SAM-) PCR for routine blood culture. J Microbiol Methods (68): 296-302 
10. Harrison EM, Paterson GK, Holden MT, Ba X, Rolo J, Morgan FJ, Pichon B, Kearns A, Zadoks RN, Peacock SJ, Parkhill J, Holmes MA. 2014. A novel hybrid SCCmec-mecC region in Staphylococcus sciuri. J Antimicrob Chemother 69:911-8.

11. Milheirico C, Oliveira DC, de Lencastre H. 2007. Update to the multiplex PCR strategy for assignment of mec element types in Staphylococcus aureus. Antimicrob Agents Chemother 51:33747.

12. Strommenger B, Braulke C, Heuck D, Schmidt C, Pasemann B, Nubel U, Witte W. 2008. spa Typing of Staphylococcus aureus as a frontline tool in epidemiological typing. J Clin Microbiol 46:574-81.

13. Enright MC, Day NP, Davies CE, Peacock SJ, Spratt BG. 2000. Multilocus sequence typing for characterization of methicillin-resistant and methicillin-susceptible clones of Staphylococcus aureus. J Clin Microbiol 38:1008-15.

14. Groome MJ, Albrich WC, Wadula J, Khoosal M, Madhi SA. 2012. Community-onset Staphylococcus aureus bacteraemia in hospitalised African children: high incidence in HIV-infected children and high prevalence of multidrug resistance. Paediatr Int Child Health 32:140-6.

15. Espadinha D, Faria NA, Miragaia M, Lito LM, Melo-Cristino J, de Lencastre H, Medicos Sentinela N. 2013. Extensive dissemination of methicillin-resistant Staphylococcus aureus (MRSA) between the hospital and the community in a country with a high prevalence of nosocomial MRSA. PLoS One 8:e59960.

16. Orth, H., Dreyer ZS., Makgotlho E., Oosthuysen W., Sinha B., Wasserman E. Characterization of Staphylococcus aureus bacteraemia at Tygerberg hospital. South Afr J Epidemiol Infect. 2013: 28(1)

17. Breurec S, Zriouil SB, Fall C, Boisier P, Brisse S, Djibo S, Etienne J, Fonkoua MC, Perrier-GrosClaude JD, Pouillot R, Ramarokoto CE, Randrianirina F, Tall A, Thiberge JM, Working Group on Staphylococcus aureus i, Laurent F, Garin B. 2011. Epidemiology of methicillin-resistant Staphylococcus aureus lineages in five major African towns: emergence and spread of atypical clones. Clin Microbiol Infect 17:160-5.

18. Celio D Santos-Junior, Antonio Verissimo and Joana Costa. The recombination dynamics of Staphylococcus aureus inferred from spA gene. BMC Microbiology. 2016. 16: 153

19. Sit PS, Teh CS, Idris N, Sam IC, Syed Omar SF, Sulaiman H, Thong KL, Kamarulzaman A, Ponnampalavanar S. 2017. Prevalence of methicillin-resistant Staphylococcus aureus (MRSA) 
infection and the molecular characteristics of MRSA bacteraemia over a two-year period in a tertiary teaching hospital in Malaysia. BMC Infect Dis 17:274.

20. Fortuin-de Smidt MC, Singh-Moodley A, Badat R, Quan V, Kularatne R, Nana T, Lekalakala R, Govender NP, Perovic O, for G-S. 2015. Staphylococcus aureus bacteraemia in Gauteng academic hospitals, South Africa. Int J Infect Dis 30:41-8.

21. Grundmann H, Aanensen DM, van den Wijngaard CC, Spratt BG, Harmsen D, Friedrich AW, European Staphylococcal Reference Laboratory Working G. 2010. Geographic distribution of Staphylococcus aureus causing invasive infections in Europe: a molecular-epidemiological analysis. PLoS Med 7: e1000215.

22. Stefani S, Varaldo PE. 2003. Epidemiology of methicillin-resistant staphylococci in Europe. Clin Microbiol Infect 9:1179-86.

23. van Hal SJ, Jensen SO, Vaska VL, Espedido BA, Paterson DL, Gosbell IB. 2012. Predictors of mortality in Staphylococcus aureus Bacteremia. Clin Microbiol Rev 25:362-86.

24. Kallen AJ, Mu Y, Bulens S, Reingold A, Petit S, Gershman K, Ray SM, Harrison LH, Lynfield R, Dumyati G, Townes JM, Schaffner W, Patel PR, Fridkin SK, Active Bacterial Core surveillance MIotEIP. 2010. Health care-associated invasive MRSA infections, 2005-2008. JAMA 304:641-8. 